\title{
LOS 6 PRINCIPIOS BÁSICOS DE PERSUASIÓN EN LOS LÍDERES ORGANIZACIONALES
}

Lilian Reza Suárez, Danny Auqui, Anny López, Janella Pinto, Ana Villavicencio 


\title{
Los 6 principios básicos de persuasión en los líderes organizacionales
}

\section{6 basic principles of persuasion organizational leaders}

\author{
Mg. Lilian Reza Suárez; Auqui Danny; López Anny; Pinto Janella; Villavicencio Ana Belén \\ Facultad de Filosofía de la Universidad de Guayaquil \\ lilianreza@gmail.com
}

\begin{abstract}
Resumen
En este ensayo se examinan los seis principios básicos de persuasión planteados por Robert Cialdini adaptados a los líderes organizacionales. A través de una encuesta realizada a 15 directivos de diversas empresas, se podrá determinar si realmente son útiles estos principios básicos de persuasión. Esta investigación la realizan los alumnos del II Ciclo de la Carrera de Psicología Organizacional, de la Universidad Católica Santiago de Guayaquil UCSG.
\end{abstract}

Palabras Claves: persuasión, líderes, organizacional, investigación

\begin{abstract}
In this essay the six basic principles about persuation held on by Robert Cialdini were adapted to the organizational leaders. Through a survey made to 15 directives of different compañies, in order to determine if these basic principles of persuation are really helpful. This investigation was carried out by students of the second term of the Organizational Psycology career of "Universidad Católica Santiago de Guayaquil” UCSG.
\end{abstract}

Keywords: persuation, leaders, organization, investigation.

\section{Introducción}

Nuestra vida cotidiana continuamente se ve afectada por procesos de influencia en las que ciertas ocasiones somos persuadidos y en otras somos los que persuadimos. Desde los permisos que tratamos de obtener de nuestros padres hasta la publicidad competitiva de dos productos casi similares.

Somos conscientes de lo susceptibles que podemos llegar a ser ante la persuasión y no solo a nivel personal se manejan este tipo de condicionamientos. En el mundo de las organizaciones existen situaciones en las que se exige utilizar la persuasión, no solo con los clientes sino también con los miembros que pertenecen a la institución. Entonces, ¿realmente serían útiles estas técnicas de persuasión por parte de los líderes de la organización? ¿Por qué?

Es por esto que a lo largo de este ensayo se analizarán las diversas técnicas de influencias sistematizadas, siguiendo los postulados propuestos por el reconocido psicólogo Robert Cialdini, determinando qué pueden aportar a los líderes organizacionales y de qué manera podemos aprovechar estas pautas de persuasión en nuestro desarrollo profesional futuro.

\section{Marco contextual}

El profesor y psicólogo Robert Cialdini, desarrolló seis principios básicos de persuasión planteados en su libro Influencia: ciencia y práctica, el cual es considerado como la investigación más básica e importante que se ha desarrollado sobre persuasión.

En dicho libro se explican los principios básicos de persuasión detalladamente. El profesor Cialdini también los llama "las 6 armas de la persuasión" y son simplemente los factores que hacen más proclive a un ser humano a decir sí a otro y aceptar algo. Por tal motivo creemos que estos principios son indispensables en los líderes organizacionales de hoy en día.

El primero de los seis principios básicos de persuasión, es el principio de Afinidad, empatía o gusto por el persuasor, esto explica la tendencia básica que tiene el comportamiento humano, es decir, el ser más propenso a aquello que nos gusta. Esto es percibido en nuestro diario vivir, por ejemplo: ser más propenso a comprarle a una amiga que a un desconocido comerciante de una empresa. Es importante no confundir esto con la relación que hay entre persuasor y persuadido.

Los líderes organizacionales deben llevar impregnado este principio si desean que sus subordinados, empleados, seguidores, etc. estén más propensos a seguir sus lineamientos $\mathrm{u}$ órdenes que a las influencias internas y externas de la organización. Un ejemplo muy común son los sindicatos que existen dentro de las organizaciones, que independientemente de cómo se gestione la empresa siempre existirán con o sin motivos valederos o justificados. Aquí se pondrá en juego el compromiso que tiene el empleado de 
seguir a un líder sindical o al líder y dueño de la empresa. Es más que obvio que aquel por quien más sienta afinidad y compromiso será a quien apoye.

El segundo principio es el principio de Reciprocidad. Es el mecanismo más básico y más fuerte de nuestra sociedad y de la mayor parte de las interacciones humanas. Es un principio tan poderoso que fácilmente puede superar en efectividad al anterior principio.

El principio de reciprocidad se basa en compensar las situaciones que nos ocurren hasta alcanzar un equilibrio. Cuando alguien nos hace un favor nos sentimos en la obligación de devolver ese favor de alguna $u$ otra manera, y nos sentimos insatisfechos o intranquilos mientras no lo compensemos. Por otra parte, la reciprocidad "negativa" se basa en castigar al sujeto o persona por una acción negativa o mal vista según el criterio del persuadido.

Este principio es clave para los directivos de una empresa, y por lo tanto para los líderes organizacionales. Todo este principio está sintetizado en: "Si obras bien, te va bien; si obras mal, te va mal". Sueldos atrasados, autoridad autócrata, malas condiciones laborables, entre otros, solo serían factores que se acumularían y "estallarían" cuando el jefe necesite algo de sus empleados. Todo este panorama sería distinto si hubiese una relación cordial entre líder y subordinado, donde el líder sea comprensivo y flexible ante los pedidos de su empleado, dando como resultado un compromiso total por parte del empleado a la empresa.

El tercer principio de persuasión es el de Compromiso y Consistencia. Cialdini plantea que las personas modifican su comportamiento si se les asignan algún tipo de responsabilidad o cargo, convirtiéndolas en personas comprometidas moral y conscientemente. Para aumentar aún más el compromiso Cialdini sugiere hacer este acuerdo o delegación por escrito o públicamente, comprometiendo en mayor nivel a la persona.

Algo muy parecido a este principio es lo que algunos líderes conocen como "empowerment" que se basa en delegar responsabilidades a sus empleados de acuerdo a sus competencias y al nivel de conocimiento o vivencia de su cargo. Como resultado los líderes organizacionales obtienen mayores resultados, mayor compromiso de los empleados con la empresa, y por sobre todo el hecho de reconocer la confianza que se depositó en ese empleado.

Un cuarto principio de persuasión es el de Aprobación Social. Este principio es uno de las más interesantes a nuestro juicio y también a criterio de los expertos del marketing. Es muy fácil de reconocer y probablemente haya sido empleado inconscientemente por alguno de nosotros, como por ejemplo: cuando usted prefiere a una marca $\mathrm{x}$ de algún producto sobre otra solo por el simple hecho de que la mayoría social lo aprueba o lo ha comprado más veces que otro producto.
Este principio está descrito como el principio por el cual nosotros seguimos o rechazamos algún lineamiento por encima de otro cuando el entorno social que nos rodea lo aprueba o lo rechaza.

Este principio actúa eficientemente cuando existe incertidumbre, y cabe recalcar que puede resultar a favor o en contra del líder, y por lo tanto a la empresa. A nuestro criterio este principio es el resultado de cómo se está gestionando la empresa, y de si se han empleado los otros 5 principios de persuasión, porque si se tiene empleados comprometidos con la empresa y con el líder, aquella incertidumbre no existirá o será muy mínima.

El quinto principio de persuasión es el de Autoridad, el cual no sólo está relacionado con el poder directo que tenga el líder de la empresa frente a sus subordinados, sino también a la credibilidad que éste posea. Por ejemplo, un médico representa una autoridad indiscutible para cada uno de sus pacientes o un policía impondrá orden y ley sin que se pueda cuestionar su decisión.

Esto también sucede dentro de una organización, el líder posee rasgos, cualidades y actitudes calificadas para administrar, organizar y dirigir a cientos de personas de la manera más óptima y favorable para cumplir con los objetivos de la empresa. Además se puede determinar si se es un buen líder a través de la disposición que los colaboradores tengan al momento de obedecerlo ya sea en las decisiones que tome a favor de la empresa o en cambios que desee implementar dentro de la empresa.

El último principio que desarrolla el reconocido psicólogo es el de Escasez, como menciona Cialdini en su obra la gente tiene que saber qué se está perdiendo si no actúa rápidamente. En el marketing esto es muy utilizado en empresas que anuncian que sus productos poseen un límite de stock, provocando la necesidad del consumidor por obtener aquel producto. Aquí lo que prima es el hecho de que el perder provoca más ansiedad de lo que se puede ganar.

En el líder organizacional, este principio puede ser usado más bien como un arma de motivación y beneficio para la empresa. Al momento de contratar personal, los prospectos deben ajustarse a las condiciones de la empresa, que en ciertos periodos no se encuentran en su mejor año de rentabilidad, por lo que depende del líder saber cómo persuadir al candidato a elegir su empresa sobre otras, informándole sobre la demanda que existe por ese cargo y que si no acepta de acuerdo a las condiciones propuestas por la empresa, hay otros 10 candidatos haciendo fila. Dentro de la organización, los ascensos son limitados por el mismo hecho de motivar a los empleados a competir por ese cargo deseado dando como resultado más eficiencia en los colaboradores. 


\section{Conclusiones}

En una encuesta realizada a 15 directivos de diversas organizaciones, se analizan los siguientes resultados: El $73 \%$ de los encuestados no conoce alguno de los seis principios de persuasión, por lo que el $93 \%$ de los mismos les gustaría conocer estos principios. Este mismo porcentaje considera que persuasión no es lo mismo que manipulación. El $100 \%$ de los encuestados perciben que somos susceptibles a la persuasión y a su vez aseguran que serían recíprocos con sus empleados.

El $80 \%$ de los encuestados creen que los seis principios básicos de persuasión son fundamentales para toda empresa, de la misma manera consideran que pueden ser utilizados tanto en el ámbito laboral como en la vida cotidiana. Este mismo porcentaje señala que utilizando estos principios pueden suponer una ventaja competitiva para su empresa. El $87 \%$ cree que una persona poco comprometida no se la debe considerar poco inteligente, indeciso o débil.

Finalmente el $80 \%$ de los encuestados consideran que serían útiles estas técnicas de persuasión en los líderes organizacionales.

Estos resultados plantean que muchos de los líderes organizacionales no conocen los principios básicos de persuasión propuestos por Robert Cialdini, pero consideran que realmente son necesarios para su desarrollo organizacional, por lo que se debe profundizar en el conocimiento y capacitación para los líderes.

\section{Referencias}

Belmar, I. (s.f). Persuasión avanzada para emprendedores. Recuperado de http://www.recursosparapymes.com/gratuito/persuasio n-avanzada-primera-parte.pdf

Cialdini, R. (2001). Influencia: Ciencia y práctica. Recuperado de https://revolucionesmlm.files.wordpress.com/2014/07/ robert-caldini-influencia-ciencia-y-practica.pdf

Jaeggi, M. (s.f). Usa estas 6 técnicas de la ciencia de la persuasión para conseguir más clientes antes que tu competencia. ¡O podrías perder tu negocio! Recuperado de http://postcron.com/es/blog/las-6tecnicas-mas-poderosas-de-la-ciencia-de-la-

persuasion/

Lodeiro, F. (2014). Influencia: Ciencia y Práctica de Robert Cialdini. Análisis, opinión y PDF del libro. Recuperado http://www.academiadeinversion.com/influenciaciencia-practica-robert-cialdini-libro-pdf/ López, M. (s.f). Influencia social: Principios básicos y tácticas de influencia. Recuperado de http://www.psicosocial.net/grupo-accioncomunitaria/centro-de-documentaciongac/fundamentos-y-teoria-de-una-psicologia- liberadora/psicologia-social/138-influencia-socialprincipios-basicos-y-tacticas-de-influencia/file . 